\section{MALNUTRITION OF THE NERVOUS SYSTEM *}

BY

\section{W. RUSSELL BRAIN, D.M., F.R.C.P. Physician to the London Hospital and the Maida Vale Hospital for Nervous Diseases}

What is meant by malnutrition of the nervous system ? The most obvious example is the deficiency in the food of some substance necessary for the maintenance of normal nervous activity, and it is with this that I am here mainly concerned. But clearly malnutrition means much more than this. The food may be adequate but its absorption from the alimentary canal may be defective ; or, though it is normal in amount and quality and normally absorbed, some metabolic disorder may interfere with its utilization or some local lesion may prevent it from reaching the nervous tissues. At one extreme dietary avitaminosis, at the other cerebral thrombosis, are causes of malnutrition of the nervous system, and between the two the distinction between disorders of nutrition and metabolism is by no means clear. But I am not here concerned with local lesions or metabolism, though neither must be altogether lost to sight. For the present purpose malnutrition may be defined as a failure of the nervous system to obtain substances necessary for its maintenance and activity as a result of defective diet or defective absorption from the alimentary canal.

If we list the food substances presumably necessary for the nutrition of the nervous system-proteins, fats, sugar, vitamins, and minerals - the large gaps in our knowledge at once become apparent. Concerning the need of the nervous system for proteins and amino-acids we know almost nothing, though recent work (Zimmerman and Ross, 1944 ; Albert and Warden, 1944 ; Weil-Malherbe, 1935) suggests that glutamic acid may be especially important for cerebral metabolism. In particular we do not know what part, if any, defective protein intake plays in causing deficiency syndromes. We know even less about the role of lipoids and mineral substances, though copper plays some part in the prevention of sway-back in sheep. Almost all we know is concerned with the metabolism of glucose by the nervous system and the part played in this by certain vitamins of the B group. Here it is worth remarking that man has taken over from the vegetable kingdom not only these vitamins but also their role in metabolism. Both aneurin and nicotinic acid are present throughout the vegetable kingdom, in plants, bacteria, yeasts, and fungianeurin being necessary for the breakdown of pyruvic acid, and nicotinic acid acting as a component of codehydrogenase (Schopfer, 1943). Indeed, these vitamins play so narrowly specific a part that they would be useless to us if our nervous systems did not metabolize carbohydrate in the same way as the plants. Moreover, we are doubly dependent upon the vegetable kingdom, for we consume the vitamins that the vegetables synthesize, and, in addition, bacteria in the intestine may be a substantial source of these vitamins by generating them in situ (British Medical Journal, 1945, 1, 879).

\section{Aneurin Deficiency Beriberi}

The view that beriberi might be due to a lack of more than one factor seems to have been disposed of by experimental work and by the observation of the correlation between the incidence of beriberi and the aneurin/non-

\footnotetext{
*Introductory Paper at a discussion at the Neurological Section of the International Congress of Medicine, Sept. 9, 1947.
}

fat-calorie ratio first noted by Williams and Spies (1938). This is well shown in the observations of Burgess (1946) upon prisoners of war. When the aneurin/non-fat-calorie ratio was above 0.3 beriberi was almost absent; when it fell below that figure the incidence of beriberi varied inversely with it (Fig. 1). .But, as Walshe (1917-18) has
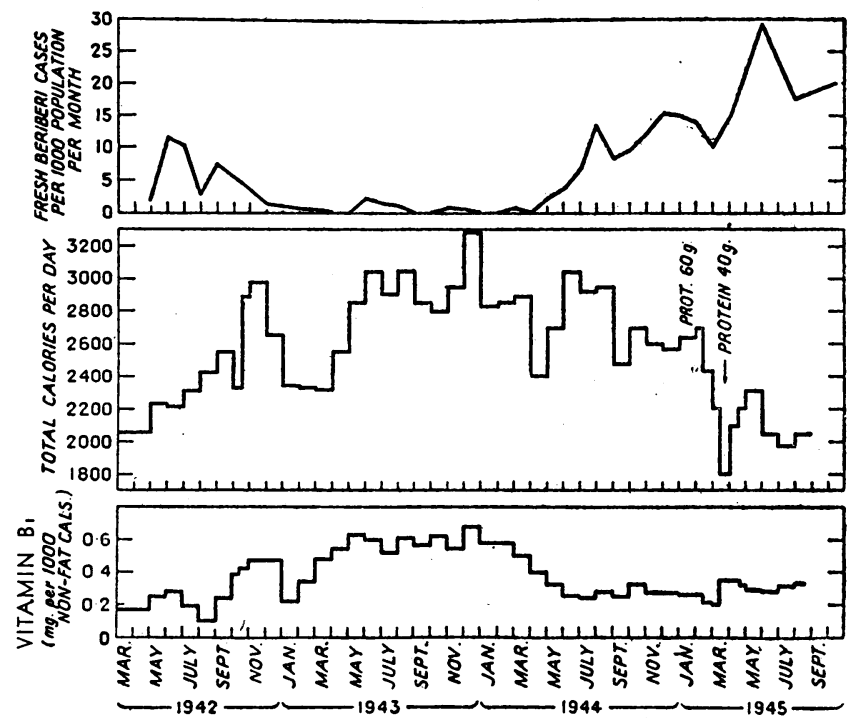

FIG. 1.-Monthly incidence of beriberi compared with estimated total calories and vitamin $B_{1} /$ non-fat-calorie ratio of diet at Changi Camp (Burgess, 1946).

pointed out, aneurin is not an antineuritic factor in the sense that it is necessary for the nutrition of the peripheral nerves, and all the evidence favours his view that the polyneuritis in beriberi is caused by an intoxication with pyruvic acid and allied intermediate products of sugar metabolism which is incomplete owing to lack of aneurin. Hence the importance of the aneurin/non-fat-calorie ratio, for beriberi will not occur in the absence of sufficient carbohydrate to metabolize into pyruvic acid. It has been suggested that diabetic polyneuritis may be due to aneurin deficiency (Rudy and Epstein, 1945), but this is unlikely, for the diabetic whose tissues cannot utilize sugar normally is in the position of a patient with a high aneurin/non-fat-calorie ratio, and Lowry and Hegsted (1945) have shown that rats rendered diabetic with alloxan require less aneurin than normal animals and show no greater tendency than controls to develop symptoms of aneurin deficiency on a defective diet.

The role of aneurin deficiency in alcoholic polyneuritis is still debatable, but the observations of Brown (1941) that a group of patients given additional aneurin recovered no more quickly than a control group on a hospital diet is surely not evidence against it. Leaving on one side the question whether the two groups were comparable, there is no reason to suppose that aneurin promotes the regeneration of damaged peripheral nerves or that it can do more even in beriberi than put an end to the intoxication of a perverted sugar metabolism. The patient whose alcoholism and gastritis are treated and who is given a full and balanced diet is therefore likely to recover, even if his polyneuritis is due to aneurin deficiency, as quickly as one given excessive doses of aneurin. For somewhat similar reasons diphtherial polyneuritis fails to respond to diphtheria antitoxin. It is well known that aneurin will not lead to full recovery in chronic beriberi, probably because, as Wright (1903) showed, in severe beriberi the posterior root ganglion cells and the anterior horn cells of the spinal cord degenerate, and when this has occurred sensory and motor symptoms will be permanent. Like Walshe (1945) I have never seen 
a patient with chronic polyneuritis from any cause benefit from aneurin, but the therapy of chronic polyneuritis is no clue to its aetiology.

\section{Wernicke's Encephalopathy}

The evidence that Wernicke's encephalopathy is due purely to aneurin deficiency seems conclusive. Epidemiologically it occurs at the same time as beriberi. According to de Wardener and Lennox (1947) neuritic, cardiac, and oedematous manifestations of beriberi were present in $79 \%$ of their patients at Changi. The pathological changes in the nervous system have been produced experimentally by aneurin deficiency (Alexander et al., 1938, 1941 ; Prados and Swank, 1942). The level of pyruvate in the blood is raised and its return to normal in response to treatment is parallel with the clinical improvement (Wortis, Bueding, Stein, and Jolliffe, 1942). Finally, aneurin is completely effective in early cases "(de Wardener and Lennox, 1947).

This raises the question why some members of a population exposed to aneurin deficiency develop encephalopathy or cerebral beriberi while others show the other manifestations alone, and why Wernicke's encephalopathy ceases to occur in an exposed population though neuritic beriberi continues (Fig. 2). Does this depend upon indi-

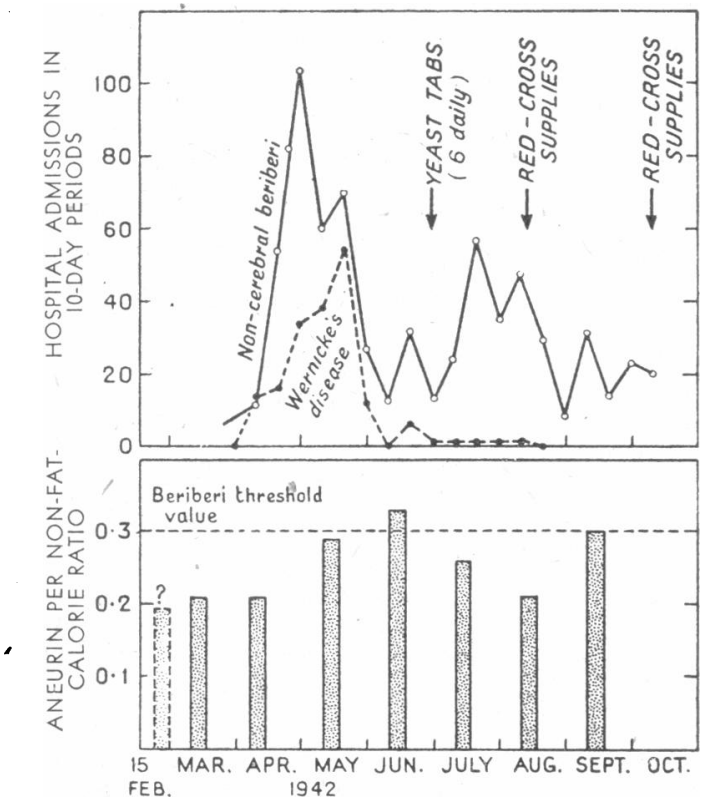

FIG. 2.-Hospital admissions of non-cerebral beriberi and Wernicke's encephalopathy, in ten-day periods, compared with ansurin/non-fat-calorie ratio of diet (mg. of aneurin per 1,000 non-fat-calories) (de Wardener and Lennox, 1947).

vidual susceptibility or upon other factors, such as rate of onset, influenced, for example, by dysentery and diarrhoea, which de Wardener and Lennox found an important predisposing cause ?

Though neurologists are concerned primarily with the neurological manifestations of aneurin deficiency it is well to emphasize that these are merely one by-product of disordered metabolism, which also profoundly affects the heart and blood vessels.

\section{Pellagra}

It is an old observation that pellagra is prone to occur in maize-eaters, and before the discovery of the B group of vitamins the cause of pellagra was thought to be an unknown toxic substance in the maize. It was then discovered that black-tongue, a disorder in dogs analogous to pellagra, could be caused by giving a diet deficient in nico- tinic acid, and cured by giving nicotinic acid to affected animals. It seemed reasonable, therefore, to ascribe pellagra to deficiency of nicotinic acid: Later work, however, shows that this view was too simple. Krehl and his fellow workers (1945a, 1945b, 1946) have found that tryptophan relieves black-tongue produced by maize. It would seem that nicotinic acid and tryptophan or foods rich in tryptophan are to some extent interchangeable as preventives of blacktongue. It is suggested that tryptophan may lead to a change in the intestinal flora in favour of the synthesis of nicotinic acid in the alimentary canal. There is a further complication in that pyridoxin deficiency disorders the metabolism of tryptophan (Axelrod, Morgan, and Lepkovsky, 1945).

A different approach to the problem has been made by Kodicek, Carpenter, and Harris (1946), who have shown that maize has a high content of a plant hormone-indole3-acetic acid, or hetero-auxine-which inhibits growth in rats and is again counteracted by nicotinic acid and tryptophan. This may be an important observation, since the auxines are present in many foodstuffs-e.g., peas, beans, and lentils, especially when sprouting-and in cultures of yeast, moulds, and bacteria (Jensen, Avery, and Burkholder, 1936). Hence the consumption of peas, beans, and lentils with the object of increasing vitamin intake may in some respects have the opposite result, and foods contaminated with moulds may similarly counteract vitamins in the food.

All the evidence supports the view that pellagra is due to deficiency of nicotinic acid in the nervous system, but when we ask why the nervous system goes short we discover how many factors are involved. Not only must the diet contain enough nicotinic acid for the needs of the body, but it must be balanced in other respects. Too much maize counteracts the nicotinic acid either because maize is relatively deficient in tryptophan or because it contains an anti-enzyme to nicotinic acid. Maize must be balanced by nicotinic acid or tryptophan or foods rich in tryptophan. Secondary pellagra introduces additional factors, since chronic alcoholism and diseases of the alimentary canal may impair the synthesis of nicotinic acid in the intestine, its absorption and its storage, or operate in other ways as yet unknown.

There is still much to be learned about antivitamins. In addition to hetero-auxine, which is an antivitamin to nicotinic acid, there exists an antivitamin to aneurin which causes Chastek paralysis, a disorder pathologically identical with Wernicke's encephalopathy, in foxes fed on raw fish (Green, Carlson, and Evans, 1942).

\section{War Neuropathies and their Problems}

It is doubtful whether the deprivations incidental to war brought to light any new deficiency syndrome, though some occurred on an unprecedentedly large scale. On the whole disappointingly little new knowledge has been gained from this rich material, mainly because the complexity of the factors involved, together with the difficulties of the circumstances, made a clear-cut scientific approach impossible. Something has already been said about beriberi and Wernicke's encephalopathy. The other principal syndromes encountered were: (1) painful feet; (2) spinal ataxia ; (3) spastic paraplegia; (4) certain cranial nerve lesions, especially retrobulbar neuritis, nerve deafness, and laryngeal palsies, which usually accompanied spinal ataxia ; and lastly (5) a rare but interesting myasthenic syndrome. I shall not deal with these syndromes in detail, but will merely make some observations upon their aetiology.

(1) Painful Feet.-This common and comparatively simple syndrome well illustrates the difficulty of establishing the aetiology of deficiency disorders in man. The pathogenesis might have been inferred from $(a)$ the association of the 
syndrome with specific dietary deficiency, $(b)$ the coincidence of its onset with that of other recognized deficiency syndromes in other persons, $(c)$ its association with other syndromes in the same patient, $(d)$ the effect of therapy. None of these has proved conclusive.

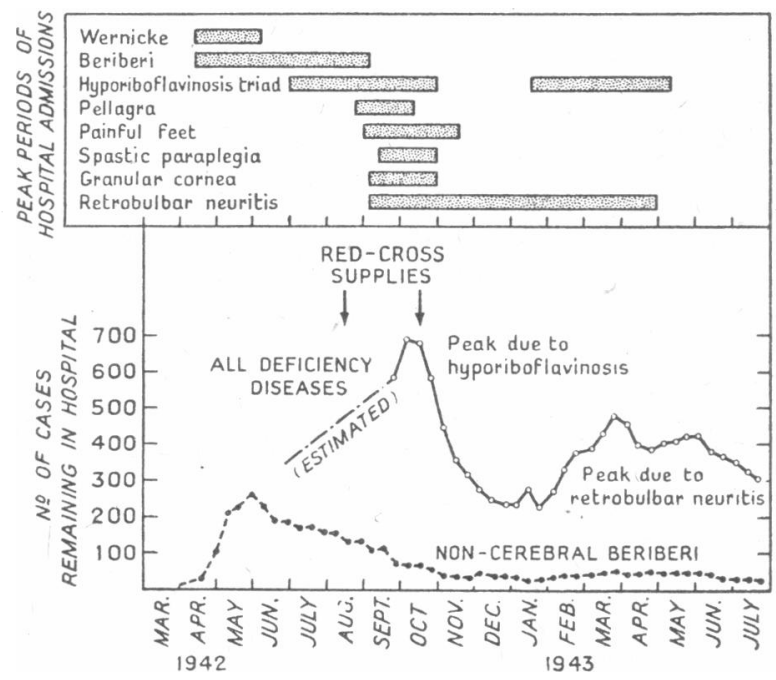

FIG. 3.-Peak periods of hospital admissions for principal deficiency diseases (de Wardener and Lennox, 1947). evidence as to its nature is conflicting and inconclusive. Stannus (1944) suggests ariboflavinosis, and symptoms of riboflavin deficiency were present in Moore's (1937) patients, but these are by no means constant. Retrobulbar neuritis may occur in association with beriberi, and so may laryngeal palsy, especially in infantile beriberi, but not deafness or spinal cord symptoms, and aneurin was of no value in treatment. Denny-Brown (1947) favours the view that this group of symptoms is pellagroid, but nicotinic acid proved of no benefit in treatment. Spillane and Scott (1945) incriminate lack of an undetermined element in the B complex. The cause is thus uncertain at present. As long ago as 1888, and again in 1897, Strachan (1897) described an epidemic in the West Indies of painful hands and feet, ataxia, retrobulbar neuritis, deafness, and weakness of the voice, these nervous signs being associated with corneal damage and muco-cutaneous lesions of the eyelids, lips, tongue and nostrils. This fifty-year-old observation provides suggestive evidence for a common origin for this group of symptoms-and shows how little we have learned since.

\section{A Myasthenic Syndrome}

A number of instances of a myasthenic syndrome, perhaps identical with Gerlier's disease, or kubisagari, have been observed among prisoners of war and attributed to dietary deficiency. I mention this because I have seen one patient in the convalescent phase. This man was never a prisoner,

(a) Dietary deficiencies were multiple, and it is difficult to select one as solely responsible, though Denny-Brown (1947) blames an exclusively cereal diet. (b) Chronologically the painful-feet syndrome occurred after the aneurin deficiency syndromes and somewhat after the onset of symptoms of hyporiboflavinosis, coinciding roughly with the peak of pellagra, spastic paraplegia, granular cornea, and the onset of retrobulbar neuritis (de Wardener and Lennox, 1947) (Figs. 3 and 4). (c) Oral and scrotal symptoms of hyporiboflavinosis preceded the outbreak (Simpson, 1946) or were associated with it in about $30 \%$ of cases (Cruickshank, 1946); retrobulbar neuritis was present in 10\% (Simpson, 1946) and $13 \%$ (Cruickshank). Oedema and polyneuritis were rare according to Cruickshank, who found no associated disease in $42 \%$. Raised blood pressure was found in $19 \%$ by Harrison and $30 \%$ by Cruickshank. (d) As to therapy, aneurin was ineffective; nicotinic acid or nikethamide gave the best results; foods rich in the $\mathrm{B}$ complex were less useful (Cruickshank). Intravenous calcium gluconate gave symptomatic relief (Harrison, 1946).

The same problems arise in connexion with the "captivity cord syndromes": (2) spinal ataxia and (3) spastic paraplegia. These syndromes occurred later in time than beriberi and Wernicke's encephalopathy. Burgess (1946) groups them together with retrobulbar neuritis and nerve-deafness as symptoms of hyporiboflavinosis, with the muco-cutaneous lesions of which they are associated. DennyBrown considers that they are parts of the
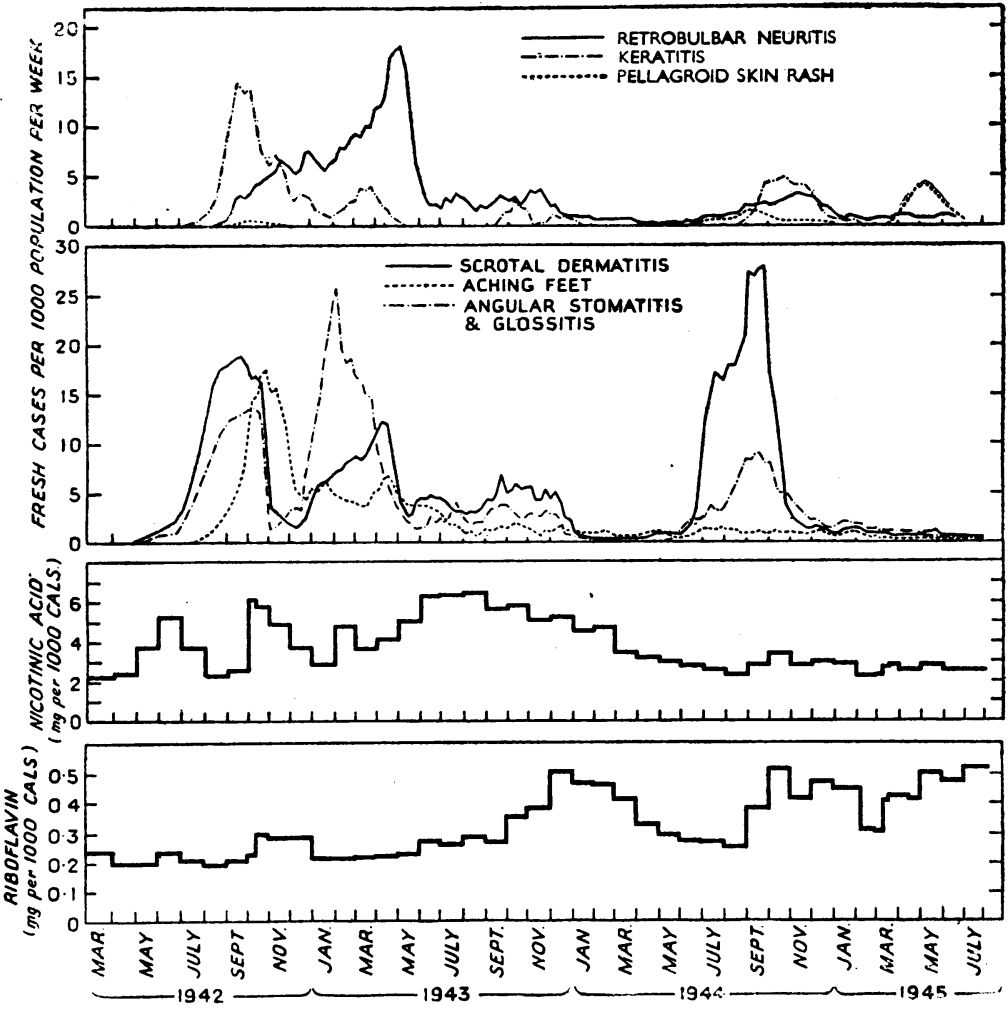

FIG. 4.-Weekly incidence of various deficiency conditions compared with nicotinicacid and riboflavin contents of diet at Changi Camp (Burgess, 1946).

syndrome of pellagra, and Spillane (1947) draws attention to the resemblance between the spastic syndrome and lathyrism. Both spinal cord syndromes responded poorly to all known forms of vitamin therapy.

(4) Cranial Nerve Palsies.-The frequent association of two or more of these symptoms-anosmia, retrobulbar neuritis, trigeminal anaesthesia, nerve-deafness, and laryngeal palsy-with or without spinal ataxia in the same patient, suggests a common cause, though the but fell ill while in the Army in Malaya after the war. $\mathrm{He}$ was not short of food, though most of it was tinned, consisting of soya sausage, bacon, beans, cheese, and fish, such as salmon. Bread was made by the field bakery. The only fresh vegetables were a small quantity of sweet potatoes and yam beans. He ate no tapioca or other cereals. His symptoms followed an acute febrile illness, and consisted of typical myasthenia involving cranial nerves and limbs, temporarily relieved by " prostigmin." He was unable to 
walk for several weeks and then slowly improved. I am not convinced that this is a deficiency syndrome. A precedent febrile illness regarded as dengue occurred in Musselman's (1945) and Katz's (1946) patients, and Katz noted that the myasthenic symptoms were in inverse relationship to the severity of the fever. In my patient an infective toxin temporarily damaging the myoneural junction seems the probable cause.

\section{Intoxication or Deficiency?}

Examples already given show that it is often difficult to distinguish between an intoxication and a deficiency. The verbal distinction is, of course, clear enough: a toxin is a harmful extra, a deficiency a harmful lack. But as soon as we get beyond the mouth difficulties arise. Food may be contaminated with a toxin, as, for example, Abyssinian wheat with flax-darnel (Brinton, 1945-6), or the food may be modified so as to become toxic, as the protein of agenized flour causes canine hysteria (Mellanby, 1947 ; Moran, 1947). Or a normal constituent of food may be toxic only in the presence of vitamin or other deficiency-e.g., maize in pellagra.

Lathyrism gives rise to a spastic paraplegia which closely resembles the spastic syndrome occasionally seen in prisoners of war. Denny-Brown believes that lathyrism has not been proved experimentally to be due to Lathyrus sativus per se, and suggests that flour made from this pea may be deficient in tryptophan and that this may neutralize the action of a vitamin, the consumption of lathyrus thus bearing the same causal relation to lathyrism that the consumption of maize or cassava does to pellagra.

But maize is toxic only in the sense that it leads to a tissue deficiency of nicotinic acid, and it might be thought that the crucial question is the state of the nervous system. Even here, however, the distinction between intoxication and deficiency is not clear-cut. Peters et al. (1945) have shown that arsenite damages the pyruvate enzyme system in the nervous system, and from this sprang the discovery of dimercaptopropanol (British anti-lewisite, BAL), which was designed to resemble the tissue thiols, to combine in their stead with trivalent arsenic and so protect them. As we have seen, aneurin deficiency also damages the pyruvate enzyme systems, and both arsenical poisoning and beriberi are accompanied by a rise in the level of blood pyruvate. Thus it would seem that arsenical poisoning may act by causing a local enzyme deficiency, and aneurin deficiency by causing a local intoxication.

In the past we have tended to think that by describing a disorder as toxic we have explained it, but it was only our ignorance of the finer processes of the metabolism of the neurone that forced us to be content with such vague conceptions as "intoxication" and "toxic polyneuritis." All that we have learned about malnutrition should teach us that whatever happens to the nervous system-not only states of avitaminosis but head injuries, infections, vascular lesions, and demyelating disorders-will need increasingly to be considered not only from the standpoint of morbid anatomy but also in terms of the chemistry of the nerve cell.

(Figs. 1 and 4 are reproduced from Dr. R. C. Burgess's paper on "Deficiency Diseases in Prisoners of War at Changi " (Lancet, Sept. 21, 1946, p. 411), and Figs. 2 and 3 from the article on "Cerebral Beriberi" by Captain H. E. de Wardener and Dr. B. Lennox (Lancet, Jan. 4, 1947, p. 11).)

\section{REFERENCES}

Albert, K. E., and Warden, C. J. (1944). Science, 100, 476

Alexander, L., Pijoan, M., Myeison, A., and Keane, H. W. (1938). Trans. Amer. neurol. Ass., 64, 135.

Green. R. G., Evans, C. A., and Wolfe, L. E. (1941) Ibid., 67, 119.

Axelrod, H. E., Morgan, A. F., and Lepkovsky, S. (1945). J. biol. Chem., 160, 155 .
Brinton, D. (1945-6). Proc. roy. Soc. Med., 39, 173.

Brown, M. R. (1941). J. Amer. med. Ass., 116, 1615.

Burgess, R. C. (1946). Lancet, 2, 411 .

Cruickshank, E. K. (1946). Ibid., 2, 369.

Denny-Brown, D. (1947). Medicine, 26, 41.

de Wardener, H. E., and Lennox, B. (1947). Lancet, 1, 11.

Green, R. G., Carlson, W. E., and Evans, C. A. (1942). J. Nutrit., 23, 165 .

Harrison, G. F. (1946). Lancet, 1, 961.

Jensen, P. B., Avery, G. S., and Burkholder, P. R. (1936). Growth Hormones in Plants. New York and London.

Katz, C. J. (1946). J. nerv. ment. Dis., 103, 463.

Kodicek, E., Carpenter, K. J., and Harris, L. J. (1946). Lancet, 2 , 491.

Krehl, W. A., Sarma, P. S., and Elvehjem, C. A. (1946). J. biol. Chem., 162, 403.

Teply, L. J., and Elvehjem, C. A. (1945a). Proc. roy. exp. Biol., N.Y., 58, 334 .

Sarma, P. S., and Elvehjem, C. A. (1945b). Science, 101,

Lowry, P. T., and Hegsied, D. M. (1945). J. Lab. clin. Med., 30, 839

Mellanby, E. (1947). British Medical Journal, 2, 288.

Moore, D. F. (1937). Lancet, 1, 1225.

Moran, T. (1947). Ibid., 2, 289.

Musselman, M. M. (1945). War Medicine, 8, 325.

Peters, R. A., and Stocken, L. A., and Thompson, R. H. S. (1945). Nature, 156, 616.

Prados, M., and Swank, R. L. (1942). Arch. Neurol. Psychiat., Chicago, 47, 626.

Rudy, A., and Exstein, S. H. (1945). J. clin. Endocrin., 5, 92.

Schopfer, W. H. (1943). Plants and Vitamins. Waltham, Mass.

Simpson, J. (1946). Lancet, 1, 959.

Spillane, J. D. (1947). Nutritional Disorders of the Nervous System. Edinburgh.

_ and Scott, G. I. (1945). Lancet, 2, 261.

Stannus, H. S. (1944). British Medical Journal, 2, 103, 140.

Strachan, H. (1897). Practitioner, 59, 477

Walshe. F. M. R. (1917-18). Ouart. J. Med., 11, 320

Walshe. F. M. R. (1917-18).

Weil-Malherbe, H. (1935). Biochem. J., 30, 665.

Williams, R. R., and Spies, T. D. (1938). Vitamin $B_{1}($ Thiamin) and its Use in Medicine. New York.

Wortis, H., Bueding, E., Stein, M. H., and Jolliffe, N. (1942). Arch. Neurol. Psychiat., Chicago, 47, 215.

Wright, H. (1903). Stud. Inst. med. Res. F.M.S., 2, No. 2.

Zimmerman, F. T.. and Ross, S. (1944). Arch. Neurol. Psychiat., Chicago, 51, 446

\section{BIOCHEMICAL APPLICATIONS OF STABLE AND RADIOACTIVE ISOTOPES*}

BY

\author{
A. S. McFARLANe, M.A., M.B., Ch.B., B.Sc. \\ National Institute for Medical Research, Hampstead
}

With but one exception the body does not discriminate between natural elements and their stable or radioactive isotopes. In addition the stable isotopes, with the exception of deuterium, have no deleterious effects on living cells even in the highest concentrations. In the case of the radioactive ones it is possible to employ such low concentrations that most human experiments can be carried out with safety, and all animal experiments with impunity, since genetic effects of the radiations can be ignored. These simple considerations have made possible to the biochemist a new kind of experimental approach which he has not been slow to use.

\section{Radioactive Phosphorus}

One of the earliest isotopes to become available was radioactive phosphorus $\left(\mathrm{P}^{32}\right)$, and of course it was administered as sodium phosphate by various routes to animals and its excretion observed and an analysis made of the skeleton and various organs to determine where and for how long it was retained. It was soon established that only a small fraction-less than $10 \%$-is excreted in twenty-four hours, and of the total amount injected only a small proportion is present in the lymph and plasma a few

*An address delivered to a joint meeting of the Physiology and Chemistry Sections of the British Association at Dundee on Sept. 2, 1947. 